tween the social elasses will disappear, perhaps in the near future. In addition to means, their probable errors, standard deviations and coefficients of variation, Dr. Gerkens provides individual values of the seven characters mentioned and several correlations. At times it seems likely that he is misled when he interprets the bimodality of a curve dependent on a small number of observations as necessarily indicative of a heterogeneous population. His data are far more extensive than those amassed by Czekanowski on the same two peoples early in the century, and they will add considerably to the knowledge of the racial situation in this little-studied area of Africa. In their presentation and statistical treatment, they maintain the standards of the native land of that pioneer anthropometrician, the great Quetelet.

\section{Illuminating Engineering Society: Annual General Meeting}

Aт the annual general meeting of the Illuminating Engineering Society which was held on May 8 at the Royal Institution, the president, I. J. Davies, presented the report of the Council for the year ending December 31, 1950. Among the points raised in the report was the decision to hold a summer meeting in Eastbourne in May 1952, on the lines of the Buxton meeting in 1950. Mr. Davies also referred to the "Register of Lighting Engineers" which has now been in operation for nearly three years; at the end of the year there were 212 names of members on the Register. At the meeting, officers and new members of council to take office in October were announced as follows: President, J. G. Holmes; Honorary Treasurer, W. J. Jones; Honorary Secretary, H. C. Weston (38 Victoria Street, London, S.W.1) ; Honorary Editor, Dr. W. E. Harper.

Honorary membership of the Society has been awarded to Dr. John W. T. Walsh, who is the only person to have been president of the Society twice, first in 1929 and again in 1947. Dr. Walsh has been for many years at the National Physical Laboratory, Teddington, where he is now a senior principal scientific officer in the Light Division; but his work has extended beyond the confines of the Laboratory ; he was, for example, closely connected with the first large-scale lighting tests carried out in factories for the Departmental Committee on Factory Lighting when that Committee was first set up in 1913. He has, too, been concerned with street lighting during recent years and served on the Departmental Committee set up by the Ministry of Transport before the Second World War. Dr. Walsh is also well known outside Great Britain, particularly for his work with the International Commission on Illumination, of which he was made a vice-president in 1948. He was general secretary of the Commission during 1921-28, and then became honorary secretary until 1931 during the late Sir Clifford Paterson's presidency.

\section{Tuatara}

THe journal T Tuatara was founded three years ago by the biological society of Victoria University College, Wellington, New Zealand, to provide a medium for articles on biological research in New Zealand which would be readily accessible to the student and the general public. Since that time a series of articles on various aspects of the New Zealand fauna and flora have appeared as well as more general articles on biological principles and current biological practice. The most recent number, for example, contains accounts of trans-oceanic dispersal of plants to New Zealand and of Now Zealand's terrestrial isopods ; a discussion of the evolutionary significance of Peripatus; a description of recent researches on the organic cycle in the soil ; and some hints on the collection and preservation of zoological specimens. Wherever possible, the articles are illustrated and add to the interest of a useful journal which deserves the support of those who are interested in New Zealand biology. Inquiries about the journal should be addressed to W. H. Dawbin, of the Zoology Department, Victoria University College, Wellington, New Zealand.

\section{Glasgow Art Gallery and Museums : Report for 1949-50}

The annual report of the Glasgow Art Gallery and Museums for 1949-50 is the first to be issued under the separate administration of the Museums and the Art Gallery. Apart from the reporting of what may be regarded as routine work, it is interesting to note that experiments in the lighting of the galleries is continuing, that an exhibition of sculpture in the open air attracted more than twenty-eight thousand visitors, and that seventeen pictures have been treated in the Art Gallery. According to modern practice, the Museums Department now deals with the scientific and historical collections. Much work has been carried out on the conservation of material. The initiation of a scheme for 'study stores' is proving successful. Begun as one for birds and one for geology, it is hoped to extend the idea to include mammals, osteology, insects and botany.

\section{History of Zinc}

THE Zinc Development Association, of Lincoln House, Turl Street, Oxford, has published "Zinc and Spelter : Notes on the Early History of Zinc", and copies will be sent to bona fide inquirers on request. The publication, written by J. M. Dawkins, contains interesting historical material and is illustrated by quotations from books often difficult to obtain. It gives an interesting and accurate account of the subject and is a real contribution to the literature of the history of chemistry and metallurgy.

\section{Canadian Awards for Postgraduate Research}

The National Research Council of Canada has recently awarded 215 scholarships, totalling 192,100 dollars, for postgraduate research in 1951-52; this is a record, both in the number of awards and total of money, the corresponding figures for last year being 192 scholarships and 140,225 dollars, respect. ively. The awards are grouped into five classes: overseas postdoctorate fellowships, seven at 2,500 dollars ; fellowships, thirty at 1,200 dollars; special scholarships, fourteen at 900 dollars; studentships, ninety-two at 900 dollans; and bursaries, seventytwo at 600 dollars. The fourteen special scholarships are for study abroad at the following universities: three each at London and Oxford, two at California, and one each at the California Institute of Technology, Cambridge, Harvard, Iowa, Ohio and Paris. The seven overseas postdoctorate fellowships are for work at British universities as follows: two each at Cambridge and London, and one each at Birmingham, Leeds and Oxford.

\section{Beit Memorial Fellowships for Medical Research}

BeIr Memorial junior fellowships for medical research, of value $£ 600$ a year, have been awarded to the following for work in particular fields at the 